\title{
Preparation of Manganese Dioxide/Polypyrrole Composite by W/O Miniemulsion and Its Electrochemical Performance
}

\author{
Zhiwei Liu*, Fangnan Liang, Ning Zhang, Youzhi Liu \\ Shanxi Province Key Laboratory of Higee-Oriented Chemical Engineering, North University of China, \\ No. 3, Xueyuan Road, Jiancaoping District, Taiyuan 030051, China \\ *E-mail: lzwww6723487@126.com
}

doi: $10.20964 / 2018.07 .14$

Received: 13 March 2018 / Accepted: 4 May 2018 / Published: 5 June 2018

\begin{abstract}
A new and convenient synthetic route of $\mathrm{W} / \mathrm{O}$ miniemulsion technology was used to prepare manganese dioxide/polypyrrole $\left(\mathrm{MnO}_{2} / \mathrm{PPy}\right)$ composites. The structures and morphologies were characterized by Fourier transform infrared spectroscopy (FTIR), X-ray diffraction (XRD), high resolution transmission electron microscope (HRTEM) and thermogravimetric analysis (TGA). The results indicated that the $\mathrm{MnO}_{2} / \mathrm{PPy}$ composite was spheroid and had average particle size of $\sim 200 \mathrm{~nm}$. The relationship between stability of the miniemulsion and the hydrophilic-lipophilic balance (HLB) was firstly evaluated. Moreover, the effects of $\mathrm{HLB}, \mathrm{KMnO}_{4}$ amount and reaction time on electrochemical properties of $\mathrm{MnO}_{2} / \mathrm{PPy}$ composites were studied by cyclic voltammetry (CV), galvanostatic charge-discharge (GCD), electrochemical impedance spectroscopy (EIS). It was found that the as-synthesized $\mathrm{MnO}_{2} / \mathrm{PPy}$ composites exhibited specific capacitance (SC) of $288.7 \mathrm{~F} \mathrm{~g}^{-1}$ at a current density (c.d.) of $0.5 \mathrm{~A} \mathrm{~g} \mathrm{~g}^{-1}$. The $\mathrm{SC}$ was still retained $91.3 \%$ after 1000 cycles at $1 \mathrm{~A} \mathrm{~g}^{-1}$. Therefore, this research proposed a W/O miniemulsion method for preparing the $\mathrm{MnO}_{2} / \mathrm{PPy}$ composites with well electrochemical properties.
\end{abstract}

Keywords: $\mathrm{MnO}_{2} / \mathrm{PPy}$ composites; W/O miniemulsion; $\mathrm{HLB}$; Electrochemical

\section{FULL TEXT}

(C) 2018 The Authors. Published by ESG (www.electrochemsci.org). This article is an open access article distributed under the terms and conditions of the Creative Commons Attribution license (http://creativecommons.org/licenses/by/4.0/). 